\title{
Design and in-vitro Evaluation of Float-adhesive Famotidine Microspheres by using Natural Polymers for Gastroretentive Properties
}

\author{
Seema Mahor ${ }^{1, *}$, Phool Chandra ${ }^{1}$, Neelkant Prasad ${ }^{2}$ \\ 'School of Pharmaceutical Sciences, IFTM University, Lodhipur Rajput, Delhi Road (NH-24), Moradabad, Uttar Pradesh, INDIA. \\ ${ }^{2}$ SGT College of Pharmacy, SGT University, Gurugram-Badli Road, Budhera, Gurugram, Haryana, INDIA.
}

\begin{abstract}
Objectives: In the present investigation a novel oral drug delivery system was developed by combining two different techniques floating and mucoadhesive system so called floatadhesive, in order to obtain a controlled system that could remain in the stomach for prolonged period and release the drug in a controlled manner. Materials and Methods: Microspheres containing Famotidine were prepared by ionic gelation method using Mimosa pudica seed mucilage as a natural mucoadhesive polymer. Sodium alginate (SA) and chitosan (CS) were incorporated as drug release modifier. The microspheres were characterized by scanning electron microscopy and evaluated by employing shape and particle size, \% drug entrapment efficiency, in vitro floating ability, in vitro mucoadhesion and in vitro drug release pattern. Results: The prepared microspheres were acceptably spherical with a mean particle size in the range of $334 \pm 1.18 \mu \mathrm{m}$ to $498 \pm 1.12 \mu \mathrm{m}$. Drug entrapment efficiency was observed in the range of $72.82 \pm 1.10 \%$ to $92.38 \pm$ $1.20 \%$. Formulations containing a combination of both mucilage and chitosan showed increased in vitro mucoadhesion and buoyancy as compared to formulations containing chitosan alone. In vitro drug release for all the formulations in $0.1 \mathrm{~N} \mathrm{HCl}$ was diffusion controlled gradually throughout $12 \mathrm{~h}$ and followed Higuchi's and Korsmeyer Peppas kinetics. The mechanism of in vitro drug release was non-fickian type controlled by swelling and relaxation of the polymer. Conclusion: The developed microspheres have dual advantages of being floating and mucoadhesive to increase oral bioavailability and releasing drug in a controlled manner, to reduce the required frequency of administration thereby promoting patient compliance.
\end{abstract}

Key words: Natural polymers, Mimosa pudica mucilage, Chitosan, Floating, Mucoadhesive, Float-adhesive, Ionic gelation.

\section{INTRODUCTION}

Oral sustained drug delivery systems are the most accepted and common systems due to various reasons like excellent patient compliance, dose reliable properties and reduction of frequency of administration. ${ }^{1}$ but in oral medications, drug bioavailability has always been a major problem which is influenced by various factors such as short (GRT) gastric residence time, ${ }^{2}$ and this is the major factor of the incomplete release of the drug and low bioavailability which leads to decreased effectiveness of the administered dose. ${ }^{3}$ A novel technique for gastric retention favor prolonged drug release in the stomach, ${ }^{4}$ because in this system dosage form can remain in the gastric environment for a longer time and improves bioavailability. ${ }^{5,6}$ But, floating dosage forms has a disadvantage that it cannot release drugs on the mucosal surface because drug release occurs at multi directions, due to this kind of release small amount of drug reaches to the target site and to achieve more efficient results the release of drug to the specific area is very important. ${ }^{7}$ Floating drug delivery system has one more
Submission Date: 14-07-2020; Revision Date: 29-11-2020; Accepted Date: 19-02-2021

DOI: 10.5530/ijper.55.2.78 Correspondence: Ms. Seema Mahor School of Pharmaceutical Sciences, Faculty of Pharmacy, IFTM University, Lodhipur Rajput, Delhi Road (NH-24), Moradabad, Uttar Pradesh, INDIA.

Phone no: +91 8586849938 Email id: seemamahor@ gmail.com

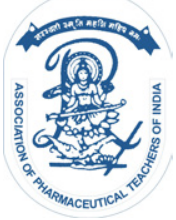

www.ijper.org 
disadvantage that it can work only when the fluid level in the gastric environment is sufficiently high because as the fluid level goes down and the stomach empties, the floating dosage form also goes down into the pylorus and the buoyancy of the dosage form may be hindered. ${ }^{8}$ This serious problem can be overcome by using a mucoadhesive polymer in the system so that the dosage form can adhere to the mucus lining of the stomach wall for a long time. This mucoadhesive system has the benefit of increased contact time with stomach linings and provides more effective absorption and bioavailability of drugs with absorption window near proximal intestine and stomach hence reduced dosing frequency. ${ }^{9}$ In this article an intelligent idea of combining two techniques such as floating and mucoadhesive has been explored by utilizing natural polymers so that dosage form can float as well adhere to the mucus lining to improve the residence time in the stomach. These polymers generally swell in gastric fluid and float, therefore, increasing the gastric residential time of formulation. ${ }^{10}$ Mucilage and gums are examples of these natural polymers. ${ }^{11}$

Previous studies focused mainly on developing floating formulations of Famotidine using synthetic polymers. However, the targeted drug delivery system of Famotidine by using natural polymers like mucilage of Mimosa pudica seed was not studied yet. First time in this article floating mucoadhesive microspheres of Famotidine using all natural excipients explored. The polymer was isolated from the seeds of Mimosa pudica family: Mimosaseae. Extracted mucilage is a polysaccharide in nature ${ }^{12}$ and has been discovered for various uses such as gelling agent, tablet binder, stabilizer and thickening agent. ${ }^{13}$ So far no studies have formulated Mimosa mucilage based floating mucoadhesive microspheres loaded with Famotidine to the best of knowledge.

Mimosa seed mucilage is chemically composed of D-xylose and D-glucuronic acid. ${ }^{14}$ It has a property of mucoadhesive polymer due to its hydrophilic and sustained release nature. ${ }^{15}$ Second polymer used in this study for the comparative study is Chitosan; a natural, non-toxic, biodegradable, biocompatible and linear polysaccharide. ${ }^{16}$ Sodium bicarbonate was used to provide buoyancy to prepared microspheres. Sodium alginate, which shrinks in low $\mathrm{pH}$ when used at higher concentrations, was used for sustained drug release in combination with chitosan. ${ }^{17,18}$ It is nontoxic, biodegradable and biocompatible. ${ }^{19}$ Alginates undergo ion tropic gelation in an aqueous solution in the presence of divalent cations like $\mathrm{Ca}^{2+}, \mathrm{Ba}^{2+}, \mathrm{Pb}^{2+}$ and trivalent cations like $\mathrm{Al}^{3+}$ due to ionic interaction and intermolecular bonding between the carboxylic acid groups located on the polymer backbone and cations. ${ }^{20}$ Famotidine is a potent $\mathrm{H}_{2}$-receptor antagonist and is widely used in the treatment of peptic ulcers in a dose of $20 \mathrm{mg}$ two times a day. The plasma half-life of Famotidine is $2.5-3 \mathrm{~h}$ has been reported in various articles; also exhibits a toxic effect in prolonged use. The low bioavailability (40-45\%) and short biological half-life (2.5-4 hr) of Famotidine following oral administration favors the development of a float-adhesive dosage form. ${ }^{21}$ Hence an idea was made in this current study to investigate the mucoadhesive ability of mucilage of Mimosa pudica seed in the form of microspheres for floating mucoadhesive microspheres of Famotidine.

\section{MATERIALS AND METHODS}

\section{Materials}

Famotidine was purchased from Yarrow Chem Pharmaceuticals, Mumbai. Sodium alginate and Chitosan were procured from the Central Institute of Fisheries Technology, Cochin. Calcium chloride and Sodium bicarbonate were purchased from Rankem Laboratory Chemical, New Delhi, India. All other reagents used were of analytical grade.

\section{Isolation of mucilage from Mimosa pudica seed}

Mucilage was isolated as per previously reported methods in various published articles with little modifications. An accurate quantity (100 g) of seeds of Mimosa pudica was weighed and processed for separating the dried brown peels from the kernel seed with the help of blander and plastic sieve were used to separate the seed. Collected seeds were then crushed lightly and soaked in the double volume of water for $12 \mathrm{~h}$, the hydrated mucilage along with seeds was taken out and spread in a thin layer on the stainless steel tray or in the dish as shown in Figure 1. After that dried in an oven at $50^{\circ} \mathrm{C}$ for $4-5 \mathrm{~h}$. The

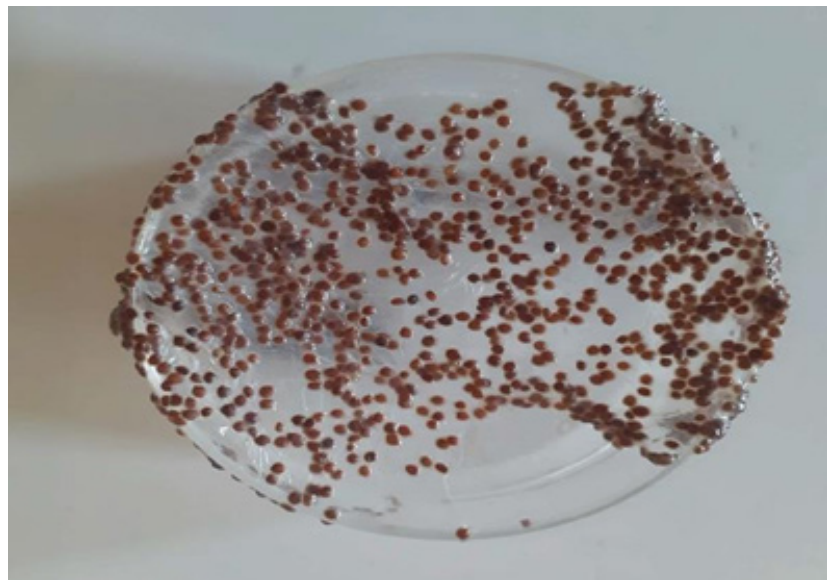

Figure 1: Hydrated seeds with a film of mucilage. 
dried mucilage was scraped from the tray by using a blade or knife and separated from the parts of seeds by passing through a sieve (18 meshes). The mucilage was further purified by winnowing to separate seed husk. The dried purified mucilage powders were preserved in desiccators. $^{22}$

\section{Preparation of Mucilage Based Float-adhesive Microspheres of Famotidine}

Batches of microspheres were prepared by ionic gelation method which involved a reaction between sodium alginate (SA) and polycationic ions like calcium chloride $\left(\mathrm{CaCl}_{2}\right)$ to produce a hydrogel network of calcium alginate. Sodium alginate in the different ratios $(2-6 \% \mathrm{w} / \mathrm{v})$ was dissolved in purified water in one beaker then drug (Famotidine) and mucilage (1:1) were added in the same beaker and stirred vigorously. After that gas forming agent Sodium bicarbonate in the ratio of $(0.5-3 \%$ of alginate) was also mixed in alginate solution. The prepared slurry was added in a thin stream to $5 \% \mathrm{w} / \mathrm{v} \mathrm{CaCl}_{2}$ solution contained in a $500 \mathrm{ml}$ beaker at a stirring speed of $1200 \mathrm{rpm} .10 \% \mathrm{v} / \mathrm{v}$ glacial acetic acid was then added slowly while stirring for ionic gelation reaction. Stirring was continued for one hour to complete the reaction and to generate spherical microspheres. Afterward, microspheres were recovered by filtration through a sintered glass filter, under vacuum, dried in a hot air oven at $60^{\circ}$ for $1 \mathrm{~h}$. Other formulations with a different drug: polymer ratios (1:1 to $1: 6 \mathrm{w} / \mathrm{w})$, varying Sodium alginate and sodium bicarbonate concentration, were prepared at different stirring speed and the same method was adopted for the preparation of Chitosan microspheres in ratios of $(1: 1$ to $1: 6 \mathrm{w} / \mathrm{w})$ keeping all the parameters constant. ${ }^{23}$ Different formulations are represented in Table 1 and 2. The ionic gelation methods used the concept of cross linking of polyelectrolyte in the presence of counter ions. ${ }^{24}$ The mechanism of this method

\begin{tabular}{|c|c|c|c|c|c|}
\hline \multicolumn{2}{|c|}{$\begin{array}{c}\text { Table 1: Batch details of Mucilage and Chitosan loaded Famotidine float-adhesive microspheres. } \\
\begin{array}{c}\text { Batch Code } \\
\text { For mucilage }\end{array}\end{array}$} & $\begin{array}{c}\text { Batch Code } \\
\text { For chitosan }\end{array}$ & $\begin{array}{c}\text { (Famotidine: Mucilage) } \\
\text { (Famotidine: Chitosan) }\end{array}$ & $\begin{array}{c}\text { Stirring Rate } \\
\text { (RPM) }\end{array}$ & $\begin{array}{c}\text { NaHCO }_{3} \\
\text { Sodium alginate } \\
\text { (\%) }\end{array}$ \\
\hline FM-1 & FC-1 & $1: 1$ & 1200 & 0.5 & 1 \\
\hline FM-2 & FC-2 & $1: 2$ & 1200 & 1.0 & 2 \\
\hline FM-3 & FC-3 & $1: 3$ & 1200 & 1.5 & 3 \\
\hline FM-4 & FC-4 & $1: 4$ & 1200 & 2.0 & 4 \\
\hline FM-5 & FC-5 & $1: 5$ & 1200 & 2.5 & 5 \\
\hline FM-6 & FC-6 & $1: 6$ & 1200 & 3.0 & \\
\hline FM-7 & FC-7 & $1: 3$ & 900 & 1.5 & 3 \\
\hline FM-8 & FC-8 & $1: 3$ & 1000 & 1.5 & 3 \\
\hline FM-9 & FC-9 & $1: 3$ & 1100 & 1.5 & 3 \\
\hline FM-10 & FC-10 & $1: 3$ & 1.5 & 3 \\
\hline
\end{tabular}

In all the batches calcium chloride concentration $5 \%$ was kept constant to obtained best gelling structure and spherical shape

\section{Table 2: Batch details of the combination of Mucilage and Chitosan loaded Famotidine float-adhesive} microspheres.

\begin{tabular}{|c|c|c|c|c|}
\hline $\begin{array}{c}\text { Batch Code } \\
\text { For mucilage and chitosan }\end{array}$ & $\begin{array}{c}\text { Drug: Polymer1: Polymer2 (Famotidine: } \\
\text { Mucilage: Chitosan) }\end{array}$ & $\begin{array}{c}\text { Stirring Rate } \\
\text { (RPM) }\end{array}$ & $\begin{array}{c}\text { NaHCO }_{3} \\
\text { Sodium alginate } \\
\text { (\%) }\end{array}$ \\
\hline FMC-1 & $1: 1: 1$ & 1200 & 0.5 & 3 \\
\hline FMC -2 & $1: 1: 2$ & 1200 & 1.0 & 3 \\
\hline FMC -3 & $1: 1: 3$ & 1200 & 1.5 & 3 \\
\hline FMC -4 & $1: 2: 1$ & 1200 & 2.0 & 3 \\
\hline FMC -5 & $1: 3: 1$ & 1200 & 2.5 & 3 \\
\hline FMC -6 & $1: 2: 2$ & 1200 & 3.0 & 3 \\
\hline FMC -7 & $1: 3: 1$ & 900 & 2.0 & 3 \\
\hline FMC -8 & $1: 3: 1$ & 1000 & 2.0 & 3 \\
\hline FMC -9 & $1: 3: 1$ & 1100 & 2.0 & 3 \\
\hline FMC -10 & $1: 3: 1$ & 1300 & 2.0 & 3 \\
\hline
\end{tabular}

In all the batches calcium chloride concentration $5 \%$ was kept constant to obtained best gelling structure and spherical shape. 
occurs through polyelectrolyte interaction between the negatively charged Alginate carboxyl group and the positively charged Chitosan amine group. ${ }^{25}$

\section{Evaluations of Float-adhesive Microspheres of Famotidine}

\section{FTIR study of prepared microspheres}

The FTIR spectra of isolated mucilage and formulation containing drug (Famotidine), mucilage and chitosan were recorded using a Fourier transforms infrared spectrophotometer (FTIR 410 PC), between ranges 450 to $4000 \mathrm{~cm}^{-1}$. The sample was gently triturated with a small amount of potassium bromide $(\mathrm{KBr})$ powder (300 mg) and compressed into pellets or discs by applying $6000 \mathrm{~kg} / \mathrm{cm}^{2}$ pressure, using manual hydraulic pressure. FTIR is done in the laboratory of NIET Greater Noida.

\section{Percentage yield}

The practical percentage yield of extracted mucilage was calculated from the weight of prepared microspheres obtained from each batch about the sum of the initial weight of raw materials. The percentage yield was calculated using the following formula. ${ }^{26}$

$\%$ Yield $=\frac{\text { Weight of product }}{\text { Total weight of excipients and drug }} \times 100$

\section{Drug entrapment efficiency}

$100 \mathrm{mg}$ of prepared microsphere were crushed carefully and incorporate in $100 \mathrm{ml}$ of simulated gastric fluid $(0.1 \mathrm{~N} \mathrm{HCl} \mathrm{pH} 1.2$ without pepsin). The prepared suspension was kept on a magnetic stirrer overnight and after that filtered through a $0.22 \mathrm{~mm}$ filter to separate shell fragments. Contents of drug were analyzed by spectrophotometer at $265 \mathrm{~nm}$. The drug entrapment efficiency of each sample was determined in triplicate by using the formula. ${ }^{27}$

Drug entrapment efficiency $(\%) \frac{\text { Actual drug content }}{\text { Theoritical amount of drugs }} \times 100$

\section{Particle size analysis}

The particle size of the prepared microspheres was determined by a laboratory scale optical microscope. Calibration of instrument was done first and make sure that 1 unit of eyepiece micrometer was equal to $12.5 \mu \mathrm{m}$. Approximately 100 microspheres were calculated under $45 \mathrm{x}$ magnifications. The average particle size of prepared microspheres was determined by using Edmondson's equation. ${ }^{28}$

$\mathrm{D}_{\text {mean }}=\frac{\mathrm{nd}}{\mathrm{n}}$

Where $\mathrm{n}=$ Number of microspheres observed and $\mathrm{d}=$ Mean size range

\section{Surface morphology}

The surface morphology of prepared microspheres was done by using the most common method of scanning electron microscopy (SEM). ${ }^{29}$ Microspheres were spread directly onto the sample stub and coated with the gold film under reduced pressure. This film work as a conducting medium on which a stream of the electron was allowed to flow and then the photograph was taken at an acceleration voltage i.e. $15 \mathrm{kV}$ by a scanning electron microscope (JEOL JSM - 6490 LA, Japan). The shape and surface texture of the microspheres were recorded.

\section{In vitro buoyancy study}

100 milligrams of the microspheres were placed in 100 $\mathrm{ml}$ of the simulated gastric fluid $(\mathrm{pH}$ 1.2) containing $0.04 \% \mathrm{w} / \mathrm{v}$ tween 20 and then stirred at $100 \mathrm{rpm}$ with a magnetic stirrer for $12 \mathrm{~h}$. After $12 \mathrm{~h}$, the layer of buoyant microspheres was separated and placed on a filter paper to absorb water. Sinking particle layers were also separated by filtration. Both types of particles (floating and sinking) were dried in desiccators until a constant weight was obtained. Both the fractions of dried microspheres were weighed and floating behavior was determined by using the following formula. ${ }^{30}$

$\%$ Buoyancy $\frac{\text { Microspheres remaied floating }}{\text { Total mass of microspheres }} \times 100$

\section{Swelling measurement}

A swelling study was performed in dissolution test apparatus II. $100 \mathrm{mg}$ of prepared microspheres were placed in the vessels containing $500 \mathrm{ml} 0.1 \mathrm{~N} \mathrm{HCl}$ (pH1.2) and allowed to rotate at $50 \mathrm{rpm}$ and swell throughout $12 \mathrm{~h}$. The microspheres were withdrawn at a fix time intervals and placed on blotting paper to remove an excess amount of water. The changes in weight of microspheres were determined at different time intervals until a constant weight was obtained. The swelling index was calculated using the following equation. ${ }^{31}$

$$
\text { Swelling index }(S)=\frac{\begin{array}{c}
\text { Weight of microspheres after swelling- } \\
\text { Intial weight of microspheres }
\end{array}}{\text { Initial weight of microspheres }} \times 100
$$

\section{In vitro mucoadhesion study}

The mucoadhesive behavior of the prepared microspheres was performed by in vitro wash-off test. In this test a $4 \mathrm{~cm} \times 4 \mathrm{~cm}$ piece of goat intestinal mucosa was taken and tied onto the paddle bottom of a USP dissolution test apparatus-II using a thread. A specified amount of microspheres, i.e. $100 \mathrm{mg}$ were spread onto the wet tissue specimen. The dissolution test apparatus was operated such that the tissue specimen was rotated at a speed of $25 \mathrm{rpm}$ in $0.1 \mathrm{~N} \mathrm{HCl}(\mathrm{pH} 1.2)$. At the end of 
$6 \mathrm{~h}$ and $12 \mathrm{~h}$, the weight of microspheres still adhering onto the tissue was calculated by using formula. ${ }^{31}$

$$
\% \text { Mucoadhesion } \frac{\text { Amount of microspheres still }}{\text { adhering }}
$$

\section{In vitro drug release study}

In vitro drug release study was performed in USP type-II dissolution test apparatus. An accurately weighed amount of microspheres equivalent to $100 \mathrm{mg}$ of Famotidine was placed in the basket of dissolution vessel containing $900 \mathrm{ml}$ of $0.1 \mathrm{~N} \mathrm{HCl}(\mathrm{pH} 1.2)$ stirred at $50 \mathrm{rpm}$ and maintained at $37 \pm 1^{\circ} \mathrm{C}$. Aliquots of samples $(5 \mathrm{ml})$ at a fixed time interval were withdrawn and $5 \mathrm{ml}$ fresh dissolution media was replaced after each withdrawal. ${ }^{32}$ The samples were diluted with $0.1 \mathrm{~N} \mathrm{HCl}$ and analyzed for Famotidine content by UV-Visible spectrophotometer at $265 \mathrm{~nm}$ against the blank. All the experimental units were analyzed in triplicate $(n=3)$.

\section{RESULTS AND DISCUSSION}

The peak of Famotidine shows an absorption band at $3505.98 \mathrm{~cm}^{-1}$ due to the N-H stretching of sulphonamide group, peaks at $1427.99 \mathrm{~cm}^{-1}$ and $1147.33 \mathrm{~cm}^{-1}$ due to $\mathrm{S}-\mathrm{O}$ stretching and $\mathrm{C}=\mathrm{S}$ stretching. The peaks of Mimosa mucilage shows the absorption band at $3400.67 \mathrm{~cm}^{-1}$ owing to -OH stretching of alcohol, a peak at 1171.28 $\mathrm{cm}^{-1}$ owing to C-O stretching of alcohol and at 2936.47 $\mathrm{cm}^{-1}$ which is due to $\mathrm{C}-\mathrm{H}$ stretching of the alkyl group. The peaks of chitosan show a strong band in the region $3239 \mathrm{~cm}^{-1}$ corresponds to $\mathrm{N}-\mathrm{H}$ and $\mathrm{O}-\mathrm{H}$ stretching of amino and hydroxyl groups. The presence of residual $\mathrm{N}$-acetyl groups was confirmed by the bands at around $1300-1633 \mathrm{~cm}^{-1}$ owing to $\mathrm{C}=\mathrm{O}$ stretching of amide group indicating there was no chemical interaction between the drug and excipients. ${ }^{33}$ as shown in Figure 2. The SEM photographs of the optimized formulations coded FM3, FC3 and FMC4 are depicted in Figure 3. The outer surface of the microspheres showed small pores and crevices which may be responsible for the drug release. On visual examination it was observed that almost all formulations of microspheres were irregular in shape and size but out of them some were acceptably spherical that formulation was taken for further evaluations.

From various evaluations it was observed that as the drug to polymer concentration increased, the product yield also increased. Sometimes the low percentage yield in some formulations may be due to product loss during the washing and handling process. The percentage yield of all formulations containing mucilage and Chitosan was found to be in the range of $70.12 \%$ to $89.58 \%$ as shown in Table 3. Data of encapsulation efficiency is Table 3. It was affected by the drug to polymer ratio and also the type of polymer used. The entrapment efficiency increased significantly with increasing polymer concentration. This is because the increase in the polymer concentration resulted in the formation of a larger microsphere so that entrapping more drugs. ${ }^{34}$ Encapsulation efficiency of mucilage-loaded microspheres was higher as compared to Chitosan-

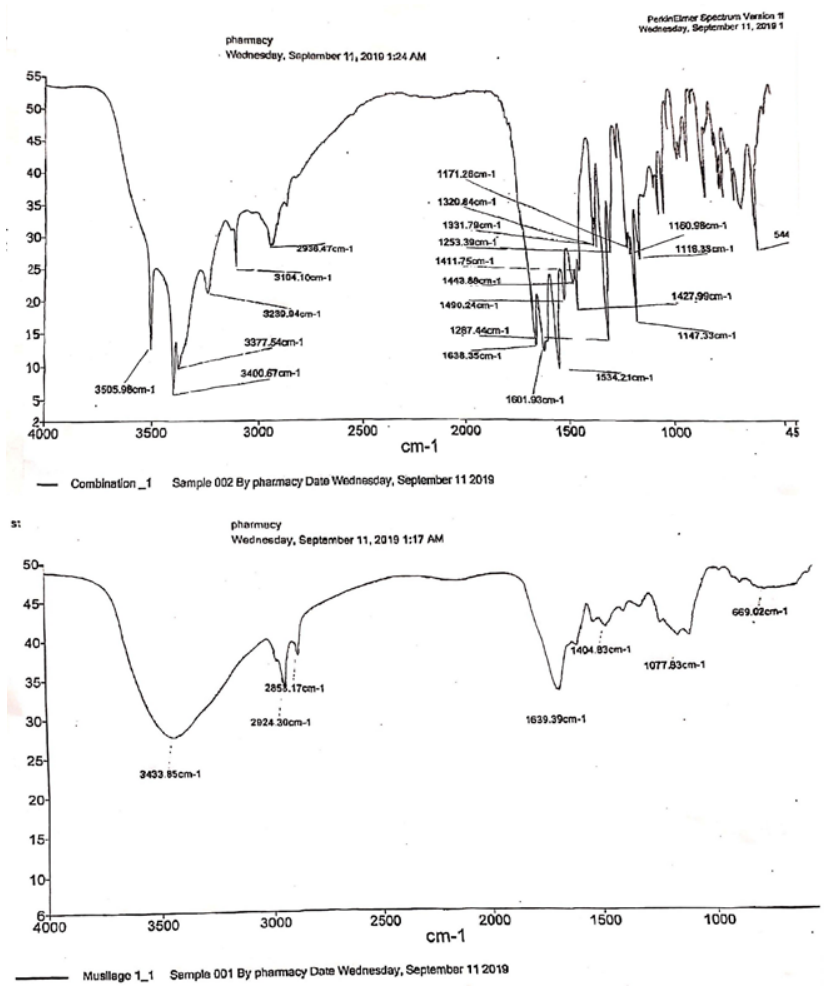

Figure 2: FTIR spectra for (a) formulation containing Famotidine, mucilage and chitosan and (b) mucilage.

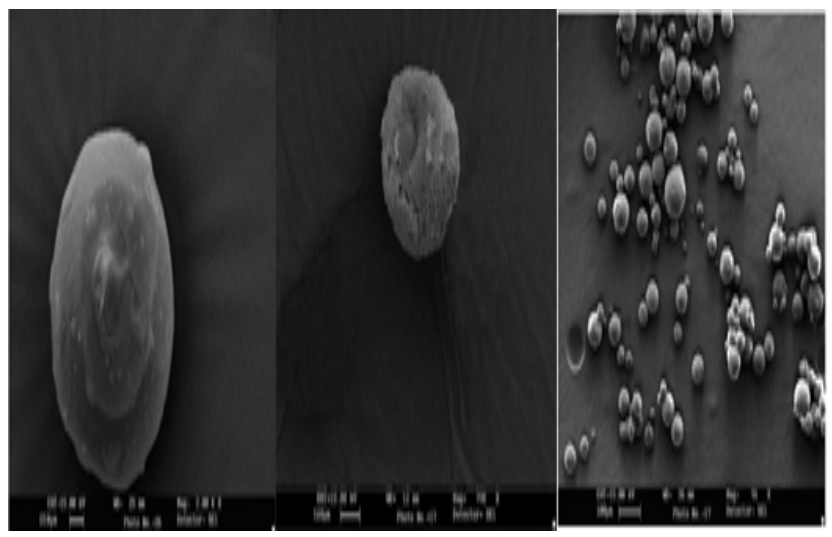

Figure 3: SEM images of Famotidine loaded microspheres (a) FC3 (Famotidine: Chitosan; 1:3); (b) FM3 (Famotidine: mucilage; 1:3); (c) FMC6 (Famotidine: mucilage: chitosan; $1: 2: 1)$. 


\begin{tabular}{|c|c|c|c|c|c|}
\hline $\begin{array}{l}\text { Formulation } \\
\text { code }\end{array}$ & $\begin{array}{l}\text { \%Yield } \\
\text { 土SD }\end{array}$ & $\begin{array}{c}\text { Average particle } \\
\text { size }^{*} \pm S D(\mu \mathrm{m})\end{array}$ & $\begin{array}{l}\% \text { Drug entrapment } \\
\text { efficiency }{ }^{*} \pm S D\end{array}$ & $\begin{array}{l}\text { Swelling } \\
\text { rate* } \%^{*}\end{array}$ & $\%$ Buoyancy \pm SD \\
\hline FM-1 & $74.36 \pm 1.5$ & $398 \pm 1.25$ & $78.12 \pm 1.25$ & 70.72 & $83 \pm 1.12$ \\
\hline FM-2 & $77.56 \pm 1.4$ & $417 \pm 1.21$ & $80.32 \pm 1.70$ & 74.58 & $87 \pm 1.29$ \\
\hline FM-3 & $82.23 \pm 1.3$ & $422 \pm 1.71$ & $83.27 \pm 1.30$ & 78.67 & $90 \pm 0.99$ \\
\hline FM-4 & $76.34 \pm 1.4$ & $434 \pm 1.23$ & $85.32 \pm 1.54$ & 80.07 & $76 \pm 2.13$ \\
\hline FM-5 & $78.76 \pm 1.4$ & $448 \pm 1.43$ & $87.43 \pm 1.34$ & 84.21 & $71 \pm 1.34$ \\
\hline FM-6 & $75.14 \pm 1.3$ & $456 \pm 1.12$ & $89.22 \pm 1.56$ & 89.37 & $68 \pm 1.34$ \\
\hline FM-7 & $80.38 \pm 1.5$ & $498 \pm 1.34$ & $80.56 \pm 1.42$ & 77.87 & $82 \pm 1.08$ \\
\hline FM-8 & $78.25 \pm 1.3$ & $484 \pm 1.67$ & $81.27 \pm 1.30$ & 77.77 & $83 \pm 1.45$ \\
\hline FM-9 & $76.68 \pm 1.4$ & $471 \pm 1.29$ & $82.34 \pm 1.56$ & 78.11 & $81 \pm 1.34$ \\
\hline FM-10 & $80.48 \pm 1.4$ & $405 \pm 1.78$ & $79.46 \pm 1.45$ & 77.82 & $83 \pm 1.18$ \\
\hline $\mathrm{FC}-1$ & $70.12 \pm 0.3$ & $334 \pm 1.18$ & $72.82 \pm 1.10$ & 64.70 & $70 \pm 1.30$ \\
\hline FC-2 & $76.43 \pm 1.1$ & $353 \pm 1.21$ & $77.12 \pm 1.18$ & 66.26 & $73 \pm 1.29$ \\
\hline FC-3 & $80.23 \pm 2.5$ & $372 \pm 1.71$ & $82.34 \pm 1.72$ & 67.03 & $78 \pm 1.49$ \\
\hline FC-4 & $83.34 \pm 3.3$ & $385 \pm 1.23$ & $80.14 \pm 1.43$ & 63.58 & $67 \pm 1.23$ \\
\hline FC-5 & $81.45 \pm 3.4$ & $391 \pm 1.43$ & $76.21 \pm 1.49$ & 61.47 & $63 \pm 1.27$ \\
\hline FC-6 & $76.32 \pm 0.8$ & $398 \pm 1.12$ & $73.45 \pm 1.38$ & 58.19 & $58 \pm 1.38$ \\
\hline FC-7 & $77.53 \pm 0.1$ & $412 \pm 1.31$ & $78.56 \pm 1.20$ & 66.21 & $80 \pm 1.10$ \\
\hline FC-8 & $82.61 \pm 2.4$ & $395 \pm 1.67$ & $79.34 \pm 1.72$ & 65.75 & $79 \pm 1.26$ \\
\hline FC-9 & $71.28 \pm 1.2$ & $384 \pm 1.29$ & $80.22 \pm 1.36$ & 64.28 & $82 \pm 1.36$ \\
\hline FC-10 & $76.24 \pm 1.3$ & $358 \pm 1.48$ & $77.34 \pm 1.63$ & 63.50 & $81 \pm 1.44$ \\
\hline FMC-1 & $78.68 \pm 1.1$ & $410 \pm 1.33$ & $73.12 \pm 1.11$ & 80.62 & $84 \pm 1.40$ \\
\hline FMC-2 & $81.34 \pm 1.3$ & $435 \pm 1.21$ & $78.32 \pm 1.18$ & 84.10 & $87 \pm 1.38$ \\
\hline FMC-3 & $85.56 \pm 2.3$ & $456 \pm 1.71$ & $81.11 \pm 1.28$ & 87.25 & $90 \pm 1.28$ \\
\hline FMC-4 & $86.11 \pm 1.8$ & $478 \pm 1.23$ & $86.32 \pm 1.18$ & 89.80 & $94 \pm 1.35$ \\
\hline FMC-5 & $87.24 \pm 2.4$ & $484 \pm 1.43$ & $89.43 \pm 1.21$ & 85.45 & $71 \pm 1.37$ \\
\hline FMC-6 & $89.58 \pm 1.7$ & $498 \pm 1.12$ & $92.38 \pm 1.20$ & 81.95 & $66 \pm 1.18$ \\
\hline FMC-7 & $88.37 \pm 2.2$ & $548 \pm 1.38$ & $81.56 \pm 1.42$ & 88.84 & $82 \pm 1.47$ \\
\hline FMC-8 & $86.29 \pm 2.5$ & $526 \pm 1.67$ & $82.38 \pm 1.20$ & 89.75 & $86 \pm 1.41$ \\
\hline FMC-9 & $85.30 \pm 1.2$ & $502 \pm 1.29$ & $84.46 \pm 1.38$ & 89.58 & $85 \pm 1.42$ \\
\hline FMC-10 & $84.22 \pm 1.2$ & $463 \pm 1.70$ & $80.23 \pm 1.10$ & 88.85 & $83 \pm 1.20$ \\
\hline
\end{tabular}

*Data are expressed as mean \pm SD.

loaded microspheres because the increase in the concentration of mucilage causes a rise in the viscosity of the aqueous phase and mucilage has higher viscosity than that of chitosan. DEE was also influenced by sodium alginate concentration used in the formulations and it was observed that at a concentration $(>3 \%)$, SA resulted in decreased drug entrapment efficiency because at higher concentrations of SA, aggregation of Chitosan occurs. ${ }^{35}$ In this study the maximum concentration for alginate was found to be $3 \% \mathrm{w} / \mathrm{v}$ and it was based on uniformity and size of microspheres.

As the polymer concentration of either mucilage or chitosan increases the particle size also increases, this is due to the increased viscosity of the medium which was responsible for decreasing the stirring efficiency due to increased interfacial tension.

The average buoyancy in percentage was found to be $68 \pm 1.34 \%$ to $94 \pm 1.35 \%$. The highest percentage buoyancy was obtained with formulation FMC4, $94 \pm 1.35 \%$, which is because the type of polymer used and an average concentration of Sodium bicarbonate taken in the formulations was responsible for increase in the buoyancy percentage.

\section{Mechanism of Floating}

In the whole process of microspheres formation cross linking of divalent calcium ions by carboxylate groups of the sodium alginate molecules occurred to form a 
jell barrier at the surface of the microspheres. ${ }^{36}$ So the released gas $\mathrm{CO}_{2}$ from the reaction of acetic acid and calcium carbonate was entrapped in the formed gel barrier that produced buoyancy in the microspheres. Because of the reaction of incorporated calcium ions with mucilage, a cross-linked three-dimensional gel network was also formed that hindered further diffusion of $\mathrm{CO}_{2}$ from the formulations and resulted in a prolonged period of floating and drug release. ${ }^{37}$ It was observed that $\mathrm{NaHCO}_{3}$ in the range of $0.5-2 \%$ demonstrated good floating ability. Upon increasing the concentration of Chitosan in low $(\mathrm{pH}$ 1.2) media, the amino group of chitosan will produce a repulsive force that leads to swelling and hydration of microspheres and due to hydration weight of the microspheres increased causes sedimentation of microspheres which reduced the percentage buoyancy of the dosage form. ${ }^{38}$

$\mathrm{NaHCO}+\mathrm{CH}_{3} \mathrm{COOH} \rightarrow \mathrm{CH}_{3} \mathrm{COONA}+\mathrm{CO}_{2}+\mathrm{H}_{2} \mathrm{O}$

It was observed that the swelling behavior of the formulations was responsible for the extension of mucoadhesion time and drug release pattern through the polymer. The swelling index was evaluated in simulated gastric fluid (pH-1.2) and it was observed that the swelling index was affected by the concentration of chitosan, mucilage as well as concentration of sodium alginate. The result shown in Table 3 indicated that with an increase in polymer concentration, the degree of swelling also increased. The higher concentration of mucilage exhibited a large number of polar groups which increased water absorption and hence, increased swelling index. ${ }^{39}$ as the concentration of chitosan increases, initially the swelling of chitosan microspheres increases in acidic media at $\mathrm{pH} 1.2$ but later on it was hindered due to presence of alginate. An increase in alginate concentration $3<\%$ resulted in a lowering of swelling index, which is due to the shrinking tendency of sodium alginate at lower $\mathrm{pH}$.

To determine the mucoadhesive characteristics of the microspheres in-vitro wash off test was carried out for all the formulations for $12 \mathrm{~h}$. The results obtained are shown in Table 4. The wash off results indicated that all the formulations having a good percentage of mucoadhesion that were ranging from $68 \%$ to $76 \%$ for formulation FM-1 - FM-10, 61\% to 73\% for formulation FC1 - FC10 and 74\% to 86\% for formulation FMC1 FMC10. The formulation containing both the mucilage and polymer FMC-4 showing the highest mucoadhesion of $86 \%$ as shown in Table 4 at the end of $12 \mathrm{~h}$. It was due to the presence of a higher proportion of mucilage and due to the anionic nature of the polymer.

In-vitro release studies of Famotidine from floating mucoadhesive microsphere were performed in simulated gastric fluid ( $\mathrm{pH}$ 1.2) In-vitro drug release of all mucilage containing microspheres formulations was in the range of $82.84 \%$ to $58.56 \%$ at the end of $12 \mathrm{~h}$ with $68 \%$ to $78 \%$ of mucoadhesion and $68 \pm 1.34 \%$ to $90 \pm 0.99 \%$ buoyancy. In all these formulations FM3 was found to be best as it releases Famotidine 69.64\%, with 76\% mucoadhesion and $92 \pm 0.99 \%$ of buoyancy at the end of $12 \mathrm{~h}$ in a sustained manner. All formulations containing chitosan shows drug release in the range of $81.48 \%$ to $32.12 \%$, with $64 \%$ to $73 \%$ of mucoadhesion and $58.19 \%$ to $67.03 \%$ of buoyancy up to $12 \mathrm{~h}$. Similarly, the formulation containing the combination of both these polymers (chitosan and mucilage at different ratio) shows the drug release in the range of $62.75 \%$ to $51.55 \%$ with $74 \%$ to $82 \%$ mucoadhesion and $71 \pm 1.37 \%$ to $94 \pm 1.35$ $\%$ of buoyancy up to $12 \mathrm{~h}$. It was found that there was a decrease in drug release with an increase in polymer content. This could be attributed to the higher degree

\begin{tabular}{|c|c|c|c|c|c|c|c|c|c|c|c|}
\hline \multirow{2}{*}{$\begin{array}{l}\text { Time } \\
\text { (h) }\end{array}$} & \multirow{2}{*}{$\begin{array}{l}\text { Initial amount of } \\
\text { microspheres } \\
\text { attached (mg) }\end{array}$} & \multicolumn{10}{|c|}{ Microspheres remaining (in \%) } \\
\hline & & FM1 & FM2 & FM3 & FM4 & FM5 & FM6 & FM7 & FM8 & FM9 & FM10 \\
\hline 0 & \multirow{3}{*}{100} & 100 & 100 & 100 & 100 & 100 & 100 & 100 & 100 & 100 & 100 \\
\hline 6 & & 83 & 84 & 87 & 81 & 80 & 78 & 91 & 90 & 90 & 87 \\
\hline \multirow[t]{2}{*}{12} & & 74 & 75 & 76 & 74 & 73 & 68 & 77 & 78 & 78 & 77 \\
\hline & & $\mathrm{FC} 1$ & $\mathrm{FC} 2$ & FC3 & FC4 & FC5 & FC6 & $\mathrm{FC7}$ & FC8 & FC9 & FC10 \\
\hline 0 & \multirow{3}{*}{100} & 100 & 100 & 100 & 100 & 100 & 100 & 100 & 100 & 100 & 100 \\
\hline 6 & & 83 & 85 & 86 & 78 & 77 & 74 & 85 & 96 & 83 & 84 \\
\hline \multirow[t]{2}{*}{12} & & 71 & 72 & 73 & 68 & 64 & 61 & 74 & 75 & 73 & 71 \\
\hline & & FMC1 & FMC2 & FMC3 & FMC4 & FMC5 & FMC6 & FMC7 & FMC8 & FMC9 & FMC10 \\
\hline 0 & \multirow{3}{*}{100} & 100 & 100 & 100 & 100 & 100 & 100 & 100 & 100 & 100 & 100 \\
\hline 6 & & 87 & 88 & 88 & 89 & 85 & 80 & 88 & 85 & 85 & 86 \\
\hline 12 & & 83 & 84 & 85 & 86 & 80 & 74 & 84 & 80 & 81 & 82 \\
\hline
\end{tabular}


of swelling upon hydration with a higher concentration of mucoadhesive polymer content in the microspheres which leads to an increase in the diffusion path length of the drug that slows down its release. The in vitro drug release profiles for formulations are shown in Figure 4-6. For better understanding the kinetics of drug release from prepared microspheres, was analyzed according to different kinetic models. Table 5 shows that drug release from all the formulations seems to fit best in the Higuchi square roots model and Korsmeyer-Peppas model. It was observed that the mucilage and chitosan ratio had a more prominent effect on percentage drug release than the mucilage/chitosan alone. Formulations

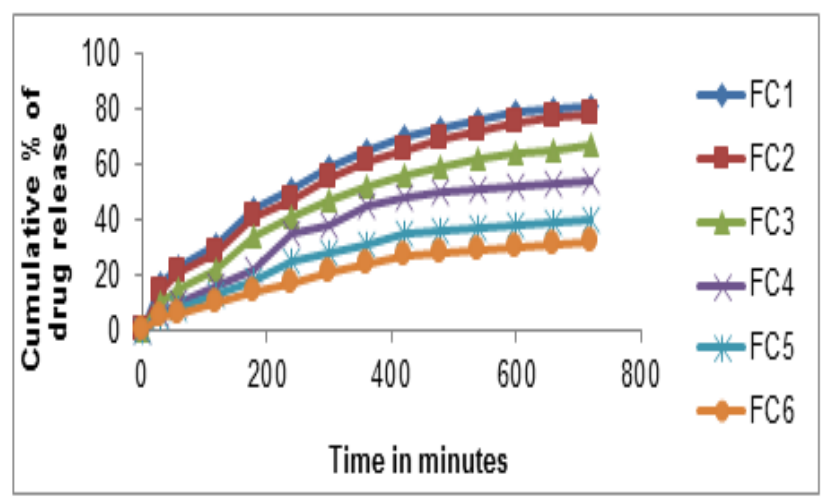

Figure 5: Cumulative percentage drug release of chitosan containing microspheres.

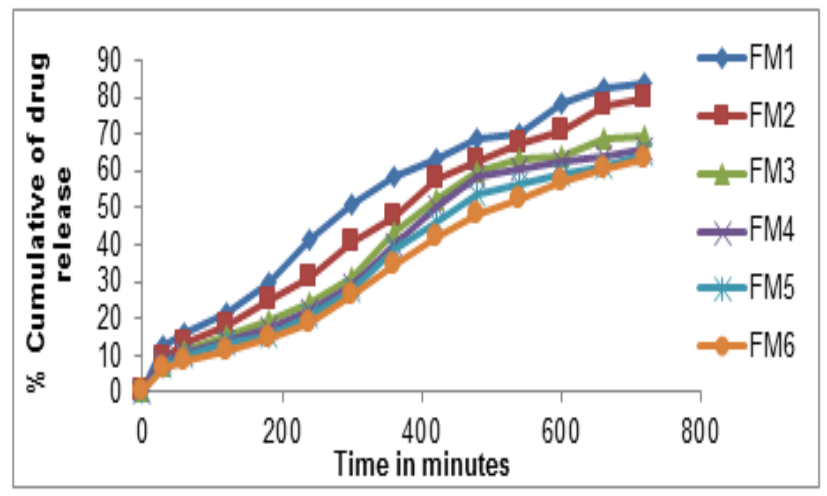

Figure 4: Cumulative percentage drug release of mucilage containing microspheres.

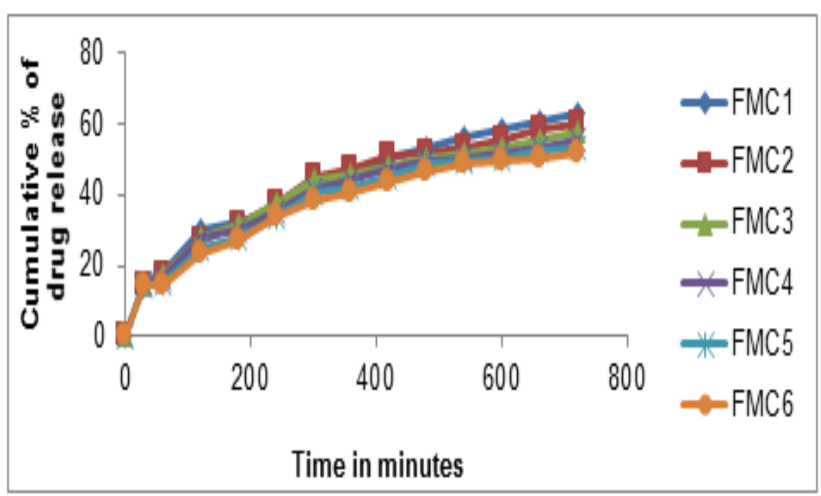

Figure 6: Cumulative percentage drug releases of chitosan and mucilage containing microsphere.

\begin{tabular}{|c|c|c|c|c|c|c|}
\hline \multirow{3}{*}{$\begin{array}{l}\text { Formulation } \\
\text { code }\end{array}$} & \multicolumn{6}{|c|}{ Release models } \\
\hline & \multirow{2}{*}{$\begin{array}{c}\text { Zero order } \\
R^{2}\end{array}$} & \multirow{2}{*}{$\begin{array}{c}\text { First order } \\
R^{2}\end{array}$} & \multirow{2}{*}{$\begin{array}{c}\text { Higuchi matrix } \\
R^{2}\end{array}$} & \multicolumn{3}{|c|}{ Koresmeyer-peppas } \\
\hline & & & & $R^{2}$ & (n) & Best fit model \\
\hline FM1 & 0.8932 & 0.9050 & 0.9891 & 0.9912 & 0.4534 & Peppas/Higuch \\
\hline FM2 & 0.8975 & 0.9224 & 0.9889 & 0.9876 & 0.4558 & Peppas/Higuch \\
\hline FM3 & 0.8830 & 0.9337 & 0.9829 & 0.9758 & 0.4641 & Peppas/Higuch \\
\hline FM4 & 0.9196 & 0.9303 & 0.9917 & 0.9908 & 0.4752 & Peppas/Higuch \\
\hline FM5 & 0.9484 & 0.9245 & 0.9897 & 0.9986 & 0.4561 & Peppas/Higuch \\
\hline FM6 & 0.9477 & 0.9369 & 0.9851 & 0.9845 & 0.4865 & Peppas/Higuch \\
\hline $\mathrm{FC} 1$ & 0.8988 & 0.9285 & 0.9881 & 0.9799 & 0.5554 & Peppas/Higuch \\
\hline FC2 & 0.9123 & 0.9293 & 0.9905 & 0.9867 & 0.5856 & Peppas/Higuch \\
\hline FC3 & 0.9085 & 0.9156 & 0.9836 & 0.9924 & 0.6334 & Peppas/Higuch \\
\hline FC4 & 0.8962 & 0.9313 & 0.9627 & 0.9873 & 0.6624 & Peppas/Higuch \\
\hline FC5 & 0.9111 & 0.9467 & 0.9787 & 0.9865 & 0.6845 & Peppas/Higuch \\
\hline FC6 & 0.9355 & 0.9587 & 0.9805 & 0.9829 & 0.7143 & Peppas/Higuch \\
\hline FMC1 & 0.9136 & 0.9072 & 0.9948 & 0.9948 & 0.4648 & Peppas/Higuch \\
\hline FMC2 & 0.8851 & 0.9031 & 0.9882 & 0.9912 & 0.4687 & Peppas/Higuch \\
\hline FMC3 & 0.8661 & 0.9123 & 0.9828 & 0.9934 & 0.4778 & Peppas/Higuch \\
\hline FMC4 & 0.8691 & 0.9168 & 0.9835 & 0.9932 & 0.4845 & Peppas/Higuch \\
\hline FMC5 & 0.8836 & 0.9039 & 0.9865 & 0.9962 & 0.4756 & Peppas/Higuch \\
\hline FMC6 & 0.8868 & 0.9119 & 0.9869 & 0.9924 & 0.4758 & Peppas/Higuch \\
\hline
\end{tabular}


with drug, mucilage and Chitosan in the ratio of 1:2:1 (optimized formulation) were capable of controlling drug release well as compared to mucilage/chitosan alone and considered as optimized formulation. When mucilage alone was used the drug release rate was rapid with a low concentration of polymer.

\section{Effect of stirring speed on particle size}

Stirring speed played an important role in the formulation of microspheres. As the agitation speed increased, the mean particle size decreased. This is due to frothing and adhesion of microspheres to the wall of the container and when agitation speed was decreased, it was stable emulsion droplets were not formed, hence larger particles were prepared. The optimum speed was found to be $1200 \mathrm{rpm}$ for the formation of microspheres at room temperature as shown in Table 3.

\section{CONCLUSION}

In this study, we successfully designed mucoadhesive floating microspheres of Famotidine for use as a gastroretentive delivery system. The in vitro drug release test indicated that the microspheres composed of either mucilage or Chitosan possessed a sustained drug release profile at the end of $12 \mathrm{~h}$. When compared with chitosan microspheres significant differences in particle size, mucoadhesive, floating ability and drug release were found. The mucilage containing microspheres demonstrated good buoyancy and adhesion properties as compare to chitosan. The efficiency of release of Famotidine from prepared microcapsules was the key factor in the successful optimization of a formulation. With a comparison between the corresponding ratios $(1: 1$ to $1: 6 \mathrm{w} / \mathrm{w})$, the mucilage polymers were found more effective than chitosan in sustaining the drug release rate. In conclusion, this study demonstrates clearly that the novel idea of a drug delivery system combining floatation with mucoadhesive properties could increase drug retention time in the gastric chamber to improve the treatment of gastric disease. In context to the intense worldwide research for natural polymer, it can be envisaged that future workers would indulge in the optimization of the various formulations of the investigating polymer to promote its commercial scale up, for effective management of peptic ulcer.

\section{ACKNOWLEDGEMENT}

The authors are thankful to Prof. M. P Pandey, ViceChancellor IFTM University, Lodhipur Rajput, Delhi Road-(NH-24)-Moradabad for the facilities and support to complete this work.

\section{CONFLICT OF INTEREST}

The authors declare no conflict of interest.

\section{ABBREVIATIONS}

MP: Mimosa pudica; SA: Sodium alginate; CS: Chitosan; RPM: Revaluation per min; GRT: Gastric retention time.

\section{REFERENCES}

1. Velmurugana S, Ali MA. Preparation and evaluation of maravirok mucoadhesive microspheres for gastro retentive drug delivery. International Journal of Pharmaceutical Science. 2015;56(7):208-14.

2. Sungthongjeen $S$, Sriamornsak $P$, Putiipipatkhachorn $S$. Design and evaluation of floating multi-layer coated tablets based on gas formation. European Journal of Pharmaceutics and Biopharmaceutics. 2008;69(4):25563.

3. Mahor S, Palani S. Preparation and evaluation of gastroretentive microspheres of Ranitidine hydrochloride. Asian Journal of Pharmaceutics. 2009;6(7):65-70.

4. Ishak RA, Awad GA, Mortada ND, Nour SA. Preparation, in vitro and in vivo evaluation of stomach specific metronidazole loaded alginate beads as local Anti-Helicobacter pylori therapy. Journal of Control Release. 2007;119(2):20714.

5. Arora S, Ali J, Ahuza A, Khar RK, Baboota S. Floating drug delivery system: A review. AAPS Pharm Sci Tech. 2005;6(3):E372-90.

6. Gattani SG, Savaliya PJ, Belgamwar VS. Floating mucoadhesive beads of Clarithromysin for the treatment of Helicobacter pylori infection. Chemical and Pharmaceutical Bulletin. 2010;58(6):782-7.

7. Bakowsky H, Richter T, Kneuer C, Hoeksta D, Rothe U, Bendas G, et al. Adhesion characteristics and stability assessment of lectin-modified liposome for site specific drug delivery. Biochimica et Biophysica Acta. 2008;1778(1):242-9.

8. Soppimath KS, Kulkarni AR, Aminabhavi TM. Development of hollow microspheres as floating controlled release systems for cardiovascular drugs. Drug Development and Industrial Pharmacy. 2001;27(6):507-15.

9. Modi A, Tayade PA. Comparative solubility enhancement profile of Valdecoxib with different solubilization approaches. Indian Journal of Pharmaceutical Sciences. 2007;69(2):274-8.

10. Elijah IN, Barbara RC. Evaluation of grewia polysaccharide gum as a suspending agent. International Journal of Pharmaceutical Sciences. 2011;3(2):168-73.

11. Jania GK, Shah DP, Prajapatia VD, Jain VC. Gums and mucilage's: Versatile excipients for pharmaceutical formulations. Asian Journal of Pharmaceutical Sciences. 2009;4(5):308-22.

12. Ahuza M, Kumar S, Yadav M. Evaluation of Mimosa seed mucilage as bucoadhesive polymer. AAPS Pharm Sci Tech. 2009;10(4):1121-7.

13. Bhargav B, Anuradha P, Narkhede S. Formulation, evaluation and optimization of carboxy methyl tamarind powder based baclofen floating matrix tablet using $3^{2}$ full factorial designs. Journal of Pharmaceutical Science and Bioscience. 2016;6(3):221-30.

14. El-menshawe SE, Kharshoum RM, Hamad DS, Halawa A. Effects of biodegradable copolymers and divalent cations on the sustained release ability of Proparanolol hydrochloride loaded biomaterial microsphere. International Journal of Pharmaceutical Sciences. 2016;8:311-7.

15. Srivastava V, Sharma A, Alam I. A review on ethanomedical and traditional uses of Mimosa pudica. International Research Journal of Pharmacy. 2012;3(2):41-4.

16. Szymanska E, Winnicka K, Wieczorec P, Sacha PT, Tryniszewska EA Influence of unmodified and $\beta$-gycerophosphate cross linked chitosan on anticandida activity of clotrimazole in semisolid delivery systems. International Journal of Molecular Sciences. 2014;15(10):17765-77. 
17. Ruocco N, Coatantini S, Guariniello S, Costantini M. Polysaccharides from the marine environment with pharmacological, cosmeceutical and nutraceutical potential. Molecule. 2016;21(5):551.

18. Yadav SK, Khan G, Bonde GV, Bansal M, Mishra B. Design optimization and characterization of chitosan fortified calcium alginate microspheres for the controlled delivery dual drugs. Artificial Cells Nanomedicine and Biotechnology. 2018;46(6):1180-93.

19. Wong TW. Alginate graft copolymers and alginate co-excipients physical mixture in oral drug delivery. Journal of Pharmacy and Pharmacology. 2011;63(12):1497-512

20. Kroll E, Winnik FM, Ziolo RF. In-situ preparation of nanocrystaline $\mathrm{Fe}^{2} \mathrm{O}^{3}$ in iron- cross linked alginate gels. Chemistry of Materials. 1996;8(8):1594-6.

21. Healther DL, Grant SM, Goa KL. Famotidine: An update review of its pharmacodynamic and pharmacokinetic properties and therapeutic use in peptic ulcer disease and other allied disease. Drugs. 1989;38:551-90.

22. Singh K, Kumar A, Lanagyan N, Ahuza M. Evaluation of Mimosa pudica seed mucilage as sustained release excipients. AAPS PharmSciTech. 2009;10(4):1121-7.

23. Reddy MS, Bhoni K, Kuppala K. Extraction and characterization of tamarind seed polysaccharide as pharmaceutical excipients. International Journal of Innovative Pharmaceutical Sciences and Research. 2015;3(9):1244-53.

24. Kapoor D, Vyas RD, Lad C, Patel M, Sharma S. Fabrication and characterization of floating microspheres of $\mathrm{H}_{2}$ receptor antagonist. The Pharmaceutical and Chemical Journal. 2015;2(3):6-15.

25. Usmiati S, Richana N, Mangunwidjaja D, Noor E, Prangdimurti E. The Using of Ionic Gelation Method Based on Polysaccharides for Encapsulating the Macromolecules. A Review. Encapsulation for Protecting the Bioactive Compounds. 2014;67:79-84.

26. Patil HS, Patil MP, Tekade BW, Thakare VM, Vijay R. Formulation and invitro Evaluation of Floating Microspheres of Acyclovir. The Archives of Pharmaceutical Science and Research. 2009;1(1):194-8.

27. Bachmann K, Sullivan TJ, Reese JH. Controlled study of the putative interaction between famotidine and theophylline in patients with chronic obstructive pulmonary disease. Journal of Clinical Pharmacology. 1995;35(5):529-35.

28. Swami NGN, Abbas Z. Preparation and in vitro characterization of mucoadhesive Hydroxypropyl guar microspheres containing Amlodipine
Besylate for nasal administration. Indian Journal of Pharmaceutical Sciences. 2011;73(6):608-14.

29. Ryan JR, Vargas R, McMahon FG, Chromos AN. Comparison of effects of oral and intravenous famotidine on inhibition of nocturnal gastric acid secretion. American Journal of Medicine. 1981;60(4):1986.

30. Rajinikanth PS, Karunagaran LN, Balasubramaniam J, Mishra B. Formulation and evaluation of clarithromycin microspheres for eradication of Helicobacter Pylori. Chemical and Pharmaceutical Bulletin. 2008;56(12):1658-64.

31. Patel JK, Bodar MS, Amin PMM. Formulation and optimization of mucoadhesive microspheres of metoclopramide. Indian Journal of Pharmaceutical Sciences. 2004;66(3):300.

32. Freitas S, Merkle HP, Gander B. Microencapsulation by solvent extraction/ evaporation reviewing the state of the art of microsphere preparation process technology. Journal of Control Release. 2005;102(2):13-8.

33. Harman JG, Limbird LE. Histamins bradykinin and their antagonists: Goodman and Gilman's The Pharmacological basis of Therapeutics, McGraw Hill Publications, New York, USA. 2001;56:645-67.

34. Trease GE, Evans MC. Textbook of pharmacognosy. $15^{\text {th }}$ ed. London: Balliere Tindall. 2002;165-72.

35. Motwari SK, Chopra S, Talegaonkar S, Kohli K, Ahmad FJ, Khar RK. Chitosan-sodium alginate nanoparticles as submicroscopic reservoirs for ocular delivery: Formulation, optimization and in vitro characterization. Europian Journal of Pharmaceutics and Biopharmaceutics. 2008;68(3):51325.

36. Shivhare UD, Singare SS, Mathur VB. Formulation and evaluation of microspheres for immediate and sustained release of different drugs using same polymer. International Journal of Pharmaceutical Development and Technology. 2014;4(1):1-7.

37. Jani GK, Shah DP. Evaluation of mucilage of Hibiscus rosasinensis Linn as rate controlling matrix for sustained release of diclofenac. Drug Development and Industrial Pharmacy. 2008;34(8):807-16.

38. Streubel A, Siepmann J, Bodmeier R. Floating matrix tablets based on low density foam powder, effects of formulation and processing parameter on release study. European Journal of Pharmaceutical Sciences. 2003;18(1):3745.

39. Honary S, Maleki M, Karami M. The effect of chitosan molecular weight on the properties of alginate/chitosan microparticles containing prednisolone. Tropical Journal of Pharmaceutical Research. 2009;8(1):53-61.

\section{PICTORIAL ABSTRACT}

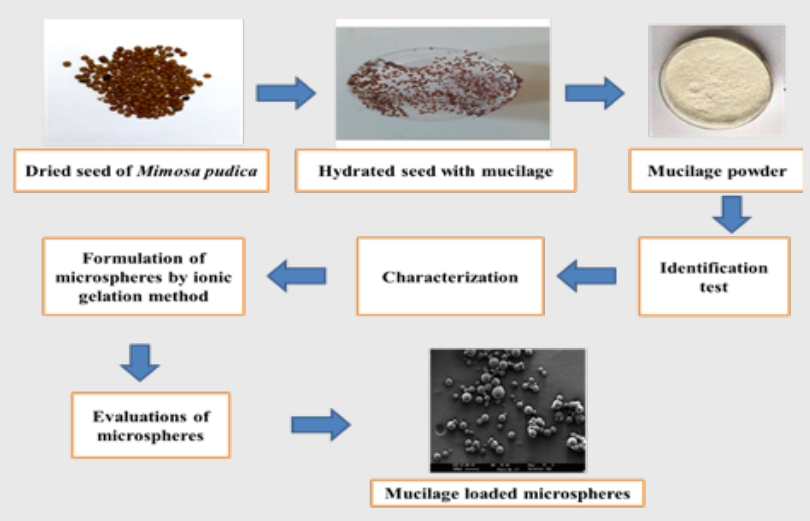

SUMMARY

In this current study we successfully prepared floatadhesive microspheres of Famotidine by using natural ingredients for the gastroretentive delivery system. The method of preparation was very simple and easy. Percentage buoyancy, mucoadhesive test and in-vitro drug release study indicated that the microspheres composed of both mucilage and chitosan possessed better results as compared to chitosan alone. Our study demonstrates that the intelligent idea of combining two techniques floating and mucoadhesive could increase the retention time of dosage form in the gastric environment to improve the treatment of gastric disease. 


\section{About Authors}

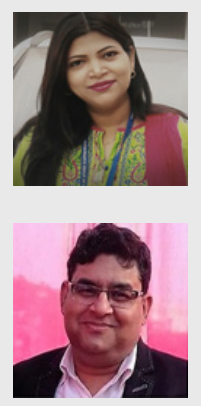

Seema Mahor, M. Pharm. in Pharmaceutics (BU, Jhansi), pursuing Ph.D. in Pharmacy, Faculty of Pharmacy, IFTM University, Moradabad, India. She has more than thirteen years of teaching experience. She is also an author of a book. She has published more than 15 research and review articles in National and International Journals. She had supervised $4 \mathrm{M}$. Pharm. research scholars. Her research area of interest covers formulation and evaluations of floating dosage form.

Dr. Phool Chandra, M. Pharm. (BU, Jhansi), Ph.D. (AKTU, Lucknow) is presently working as an Associate Professor at the Department of Physiology \& Pharmacology, School of Pharmaceutical Sciences, IFTM University, Moradabad, India. He has fifteen years of teaching and research experience. $\mathrm{He}$ is the author of two books and five book chapters with different publishers of International repute. He has published more than 50 research and review articles in National and International Journals. He is also, the editorial member of different Journals of National and International repute. He had supervised $22 \mathrm{M}$. Pharm. research scholars and presently, he is supervising three M. Pharm. and six Ph.D. research scholars. He is a member of BOS of IFTM University and other Universities. Also, He is Alumni of Jawahar Navodaya Vidyalaya Unnao and Sultanpur (UP), India.

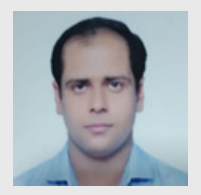

Dr. Neelkant Prasad, Ph.D. in Pharmaceutics (Pharmacy), has been engaged in teaching and research since September 2008. He is currently working with SGT College of Pharmacy, SGT University, Budhera, Gurugram, Haryana, India-122505. His research area focuses on liposomal drug delivery system, dissolution and bioavailability enhancement of poorly water soluble drugs, and analytical method development and validation.

Cite this article: Mahor S, Prasad N, Chandra P. Design and in-vitro Evaluation of Float-adhesive Famotidine Microspheres by using Natural Polymers for Gastroretentive Properties. Indian J of Pharmaceutical Education and Research. 2021;55(2):407-17. 